\title{
Rethinking Basic Concepts - Hydrogenation of Alkenes Catalyzed by Bench-Stable Alkyl Mn(I) Complexes
}

\section{Stefan Weber, ${ }^{\dagger}$ Berthold Stöger, ${ }^{\ddagger}$ Luis F. Veiros, ${ }^{\circledR}$ Karl Kirchner ${ }^{*,+}$}

†Institute of Applied Synthetic Chemistry and `X-ray Center, Vienna University of Technology, Getreidemarkt 9, A-1060 Vienna, AUSTRIA

${ }^{s}$ Centro de Química Estrutural, Instituto Superior Técnico, Universidade de Lisboa, Av. Rovisco Pais No. 1, 1049-001 Lisboa, PORTUGAL

\begin{abstract}
An efficient additive-free manganese-catalyzed hydrogenation of alkenes to alkanes with molecular hydrogen is described. This reaction is environmentally benign and atom economic, implementing an inexpensive, earth abundant non-precious metal catalyst. The most efficient pre-catalyst is the bench-stable alkyl bisphosphine $\mathrm{Mn}(\mathrm{I})$ complex fac- $\left[\mathrm{Mn}(\operatorname{dippe})(\mathrm{CO})_{3}\left(\mathrm{CH}_{2} \mathrm{CH}_{2} \mathrm{CH}_{3}\right)\right]$. The catalytic process is initiated by migratory insertion of a $\mathrm{CO}$ ligand into the Mn-alkyl bond to yield an acyl intermediate which undergoes rapid hydrogenolysis to form the active $16 \mathrm{e} \mathrm{Mn}(\mathrm{I})$ hydride catalyst $\left[\mathrm{Mn}(\right.$ dippe $\left.)(\mathrm{CO})_{2}(\mathrm{H})\right]$. A range of mono- and disubstituted alkenes were efficiently converted into alkanes in good to excellent yields. The hydrogenation of 1-alkenes and 1,1-disubstituted alkenes proceeds at $25^{\circ} \mathrm{C}$, while 1,2 -disubstituted alkenes require a reaction temperature of $60^{\circ} \mathrm{C}$. In all cases, a catalyst loading of $2 \mathrm{~mol} \%$ and a hydrogen pressure of 50 bar was applied. A mechanism based on DFT calculations is presented.
\end{abstract}

One of the fundamental research goals in modern chemistry is the development of sustainable, efficient and selective syntheses. Accordingly, it is quite important to perform reactions under catalytic conditions and to replace precious metal catalysts by Earth abundant non-precious metal catalysts. ${ }^{1}$ In particular base metals such as iron and manganese are promising candidates as these belong to the most abundant metals in the Earth crust, are inexpensive, and exhibit a low environmental impact. In this context, atom-efficient and clean processes which permit access to a green synthesis of valuable products such as alkanes, alcohols and amines is the hydrogenation of olefins, alkynes, carbonyl compounds, imines and nitriles with molecular hydrogen are of paramount importance. ${ }^{2,3}$ While iron, cobalt, and nickel hydrogenation catalysts had been subject of intense investigation over the past decade, ${ }^{4-13}$ low valent $\mathrm{Mn}(\mathrm{I})$ catalysts just appeared in 2016 as new but very powerful players in this field. ${ }^{8,9,10,11,15}$ The latter are typically substitutionally inert $18 \mathrm{e}^{-}$ complexes bearing two or three CO ligands and bi- and tridenate N, C, S, and P-donor ligands, respectively (Scheme 1) where substrate binding occurs in an outer-sphere fashion. Thus, these types of complexes are active only for the hydrogenation of polar multiple bonds such as nitriles, imines, and carbonyl compounds, while alkenes are not hydrogenated. In fact, examples of manganese catalysts which are capable of hydrogenating unactivated $\mathrm{C}=\mathrm{C}$ double bonds are exceedingly rare. ${ }^{16}$

Scheme 1. Structural Motifs of Most Mn(I) (De)hydrogenation Catalysts $(\mathrm{X}=\mathrm{Cl}, \mathrm{Br}, \mathrm{H})$
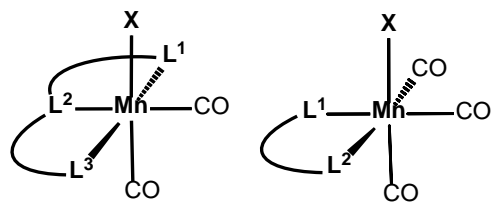

We describe here the synthesis and catalytic activity of new well-defined and bench-stable alkyl carbonyl Mn(I) complexes of the type fac-[Mn(dpre)(CO) $3(\mathrm{R})]$ (dpre = 1,2-bis(di-n-propylphosphino)ethane, $\mathrm{R}=\mathrm{CH}_{3}, \mathrm{CH}_{2} \mathrm{CH}_{3}, \mathrm{CH}_{2} \mathrm{CH}_{2} \mathrm{CH}_{3}$ ) and fac$\left[\mathrm{Mn}\right.$ (dippe) $(\mathrm{CO})_{3}\left(\mathrm{CH}_{2} \mathrm{CH}_{2} \mathrm{CH}_{3}\right)$ (dippe = 1,2-bis(di-iso-propylphosphino)ethane) for the hydrogenation of alkenes with molecular hydrogen. We take advantage of the fact that (i) CO ligands of $\mathrm{Mn}(\mathrm{I})$ alkyl carbonyl complexes are known to undergo migratory insertions to form acyl complexes if strong field ligands such as $\mathrm{CO}$ or tertiary phosphines are present - a well-known textbook reaction. ${ }^{17}$ and (ii) that hydrogenolysis of a transition-metal acyl complexes affords aldehydes and metal hydride complexes - typically the final step in both stoichiometric and catalytic hydroformylations of alkenes. ${ }^{18}$ Accordingly, the catalytic process is initiated by migratory insertion of a CO ligand into the Mn-alkyl bond to yield acyl intermediates which undergo rapid hydrogenolysis to create the active $16 \mathrm{e}^{-} \mathrm{Mn}(\mathrm{I})$ hydride catalysts (Scheme 2). 
Scheme 2. Formation of a Coordinatively Unsaturated Mn(I) Hydride Species via Alkyl Migration and Hydrogenolysis of an Acyl Intermediate

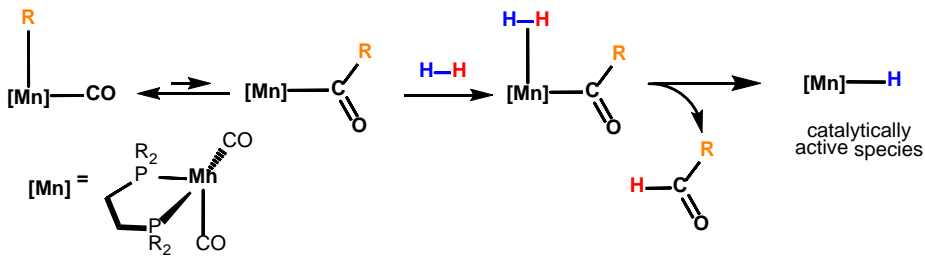

The new alkyl $\mathrm{Mn}(\mathrm{I})$ complexes fac- $\left[\mathrm{Mn}(\mathrm{dpre})(\mathrm{CO})_{3}(\mathrm{R})\right]\left(\mathrm{R}=\mathrm{CH}_{3}(\mathbf{3}), \mathrm{CH}_{2} \mathrm{CH}_{3}(4), \mathrm{CH}_{2} \mathrm{CH}_{2} \mathrm{CH}_{3}(5)\right)$ and fac$\left[\mathrm{Mn}(\right.$ dippe $\left.)(\mathrm{CO})_{3}\left(\mathrm{CH}_{2} \mathrm{CH}_{2} \mathrm{CH}_{3}\right)\right]$ (6) were obtained by treatment of fac-[Mn(dpre) $\left.(\mathrm{CO})_{3}(\mathrm{Br})\right]$ (1) and fac$\left[\mathrm{Mn}(\right.$ dippe $\left.)(\mathrm{CO})_{3}(\mathrm{Br})\right](2)$ with $\mathrm{NaK}$ (3 equiv) and subsequent addition of $\mathrm{CH}_{3} \mathrm{I}, \mathrm{CH}_{3} \mathrm{CH}_{2} \mathrm{Br}$, and $\mathrm{CH}_{3} \mathrm{CH}_{2} \mathrm{CH}_{2} \mathrm{Br}$, respectively, in moderate to good isolated yields (Scheme 3). All complexes are bench-stable for at least 4 weeks in the presence of air. They were fully characterized by ${ }^{1} \mathrm{H},{ }^{13} \mathrm{C}\left\{{ }^{1} \mathrm{H}\right\}$ and ${ }^{31} \mathrm{P}\left\{{ }^{1} \mathrm{H}\right\}$ NMR and IR spectroscopy, and high-resolution mass spectrometry. In addition, the molecular structure of 6 was determined by X-ray crystallography. A structural view is depicted in Scheme 3 with selected bond distances and angles given in the caption.

Scheme 3. Synthesis of fac- $\left[\mathrm{Mn}\left(\mathrm{R}_{2} \mathrm{PCH}_{2} \mathrm{CH}_{2} \mathrm{PR} 2\right)(\mathrm{CO})_{3}\left(\mathrm{R}^{\prime}\right)\right](3-6)$ and Structural View of 6 showing 50 \% Ellipsoids (Most H Atoms Omitted for Clarity). ${ }^{a}$

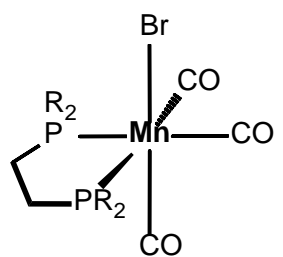

$1 \mathrm{R}=n \mathrm{Pr}$ $2 \mathrm{R}=i \mathrm{Pr}$

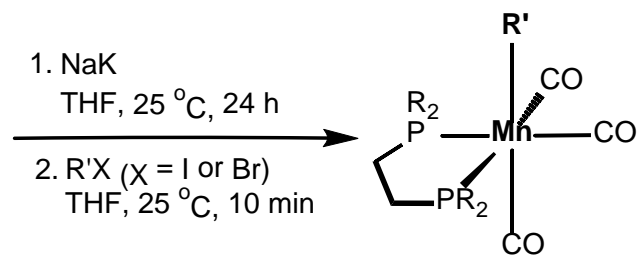

$3 \mathrm{R}=n \mathrm{Pr}, \mathrm{R}^{\prime}=\mathrm{CH}_{3}(64 \%)$

$4 \mathrm{R}=n \mathrm{Pr}, \mathrm{R}^{\prime}=\mathrm{CH}_{2} \mathrm{CH}_{3}(12 \%)$

$5 \mathrm{R}=n \mathrm{Pr}, \mathrm{R}^{\prime}=\mathrm{CH}_{2} \mathrm{CH}_{2} \mathrm{CH}_{3}(32 \%)$

$6 \mathrm{R}=i \mathrm{Pr}, \mathrm{R}^{\prime}=n_{\mathrm{Pr}}(67 \%)$

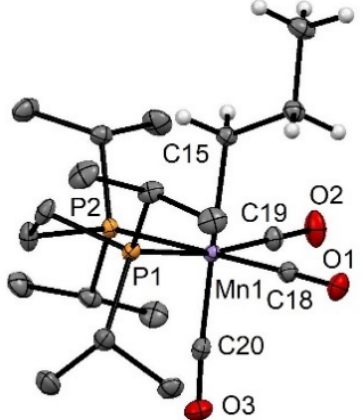

$\mathrm{O} 3$

${ }^{\text {a }}$ Selected bond distances ( $\AA$ ) and angles $\left({ }^{\circ}\right)$ : Mn1-C15 2.187(1), Mn1-C18 1.803(1), Mn1-C19 1.799(1), Mn1-C20 1.798(1), Mn1P1 2.3224(5), Mn1-P2 2.3324(5), P1-Mn1-P2 85.53(2).

The catalytic performance of complexes 3-6 and the known $\mathrm{Mn}(\mathrm{I})$ complexes fac- $\left[\mathrm{Mn}(\right.$ dippe $\left.)(\mathrm{CO})_{3}(\mathrm{H})\right](7),{ }^{19}\left[\mathrm{Mn}(\mathrm{CO})_{5}\left(\mathrm{CH}_{3}\right)\right]$ $(8)^{20}$ and fac- $\left[\mathrm{Mn}(\mathrm{bipy})(\mathrm{CO})_{3}\left(\mathrm{CH}_{3}\right)\right](\mathbf{9})^{21}$ as well as fac- $\left[\mathrm{Mn}(\mathrm{dpre})(\mathrm{CO})_{3}(\mathrm{H})\right](\mathbf{1 0})^{22}$ was then investigated for the hydrogenation of 1-dodecene (11) as model substrate (Scheme 4). Selected optimization experiments are depicted in Table 1. With complexes 3-6 as precatalysts and a catalyst loading of $2 \mathrm{~mol} \%$ at $100^{\circ} \mathrm{C}$ and a hydrogen pressure of $50 \mathrm{bar} \mathrm{H}_{2}$ in toluene for $18 \mathrm{~h}$, dodecane was obtained in essentially quantitative yield (Table 1, entries 1-4). Under the same reaction conditions complexes 7-10 were catalytically inactive and no reaction took place even when the catalyst loading was increased to $4 \mathrm{~mol} \%$ (Table 1, entries 5-8). This clearly emphasizes that strongly electron donating co-ligands such as aliphatic bisphosphines are required to achieve high catalytic activity. Moreover, coordinatively saturated and inert hydride complexes $\mathbf{7}$ and $\mathbf{1 0}$ are inactive due to the lack of a vacant coordination site and are no intermediates in the catalytic process. At $40{ }^{\circ} \mathrm{C}$ and a catalyst loading of $2 \mathrm{~mol} \%$ in diethyl ether as solvent complex 3 was no longer catalytically active, while complexes 4-6 were still efficient to convert 1-dodecene to dodecane in quantitative yield (Table 1, entries 912). It has to be noted that the rate of alkyl migration follows the order $n \mathrm{Pr}>\mathrm{Et}>\mathrm{Me}$ as established by Moss and co-workers some years ago. ${ }^{23}$ Finally, at $25^{\circ} \mathrm{C}$ complexes 3-5 were no longer active, whereas with complex 6 dodecane was isolated in 99\% yield (Table 1, entries 
13-15) suggesting that sterically demanding and very electron rich bisphosphines facilitate the catalytic reaction. Lowering the catalyst loading of 6 to $1 \mathrm{~mol} \%$ led to a slight decrease in catalytic activity yielding dodecane in $87 \%$ yield (Table 1, entry 16 ).

\section{Scheme 4. $\mathrm{Mn}(\mathrm{I})$ Complexes Tested as Catalysts}

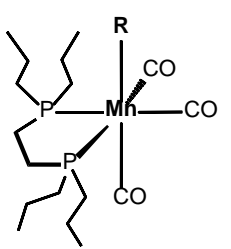

$3 \mathrm{R}=\mathrm{CH}_{3}$

$4 \mathrm{R}=\mathrm{CH}_{2} \mathrm{CH}_{3}$

$5 \mathrm{R}=\mathrm{CH}_{2} \mathrm{CH}_{2} \mathrm{CH}_{3}$<smiles></smiles>

8

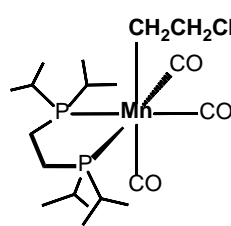

6

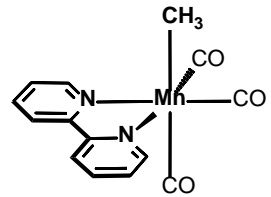

9

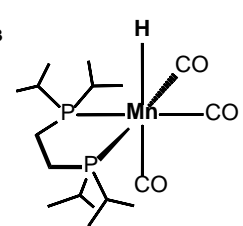

7

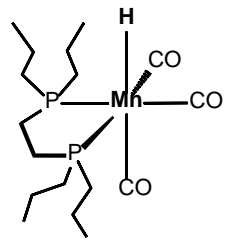

10

Having determined 6 as the most active catalyst and to prove its general applicability, various substrates have been tested to establish scope and limitations (Table 2). The substrate scope was expanded to a variety of monosubstituted alkenes, 1,1-disubstituted alkenes and cis- and trans-1,2-disubstituted alkenes. Tri- and tetrasubstituted alkenes could not be hydrogenated. Terminal alkenes and allylic alcohols 12-22 as well as the 1,1-disubstituted alkanes 23 and 26 were already reduced to the corresponding alkanes in $83-99 \%$ yields at $25^{\circ} \mathrm{C}$ with a catalyst loading of $2 \mathrm{~mol} \%, 50$ bar hydrogen pressure, reaction times between 18 to $24 \mathrm{~h}$ in diethyl ether as solvent (Table 2). The only exception is 4-vinylpyridine (24) where the yield was only $39 \%$. There was no indication of polymerization of this thermally unstable substrate underlining the mild reaction conditions of the catalytic protocol. In the case of 26 , only the terminal double bond was hydrogenated. Complete hydrogenation of internal alkenes such as trans- and cis-stilbenes $(\mathbf{2 8 , 2 9 )}$ and cyclic substrates such as $1 H$-indene (27), furan-2,5-dione (31), 2-ethoxy-3,4-dihydro-2 $H$-pyran (27) and 1,5-cyclooctadiene (33) could be achieved although a higher temperature $\left(60^{\circ} \mathrm{C}\right)$ was required. In the case of $(E)$-4-phenylbut-3-en-2-one (34) also the carbonyl moiety was hydrogenated. The catalytic protocol shows high functional group tolerance and halides, hydroxy groups, ethers, esters and even very sensitive anhydrides were well tolerated. No reaction took place with alkenes bearing carboxylic acid (35) and nitrile (36) moieties, respectively.

The reaction mechanism was explored in detail by means of DFT calculations, ${ }^{24}$ with propene taken as substrate and 6 (A in the calculations) as pre-catalyst. The free energy profile for the initiation process, where the active catalyst is formed, is depicted in Figure 1. The first step is the migration of the $\mathrm{CH}_{2} \mathrm{CH}_{2} \mathrm{CH}_{3}$ ligand in complex $\mathbf{A}$ to the carbonyl $\mathrm{C}$-atom of an adjacent $\mathrm{CO}$ ligand. This occurs in an easy step with a barrier of only $11 \mathrm{kcal} / \mathrm{mol}$ producing intermediate $\mathbf{B}$, an acyl species stabilized by an agostic C-H bond. This transformation is slightly endergonic by $6 \mathrm{kcal} / \mathrm{mol}$. Addition of dihydrogen affords complex $\mathrm{D}$ bearing a $\kappa^{2}-\mathrm{H}_{2}$ ligand. Coordination of $\mathrm{H}_{2}$ has a barrier of $9 \mathrm{kcal} / \mathrm{mol}\left(\mathrm{TS}_{\mathrm{CH}}\right.$ ) and a free energy balance of $\Delta G=7 \mathrm{kcal} / \mathrm{mol}$, from the pair of molecules in $\mathrm{C}$ to the dihydrogen complex D. Finally, $\mathrm{H}$-atom transfer from dihydrogen to the $\mathrm{C}$-atom of the acyl ligand produces $\mathrm{E}$, a $\mathrm{C}-\mathrm{H} \sigma$-complex of butanal. This last step has a barrier of only $3 \mathrm{kcal} / \mathrm{mol}$ and it is thermoneutral. The catalytically active species $\mathbf{F}$ results from ligand exchange from butanal to one molecule of propene which is thermodynamically very favorable by $-15 \mathrm{kcal} / \mathrm{mol}$. 


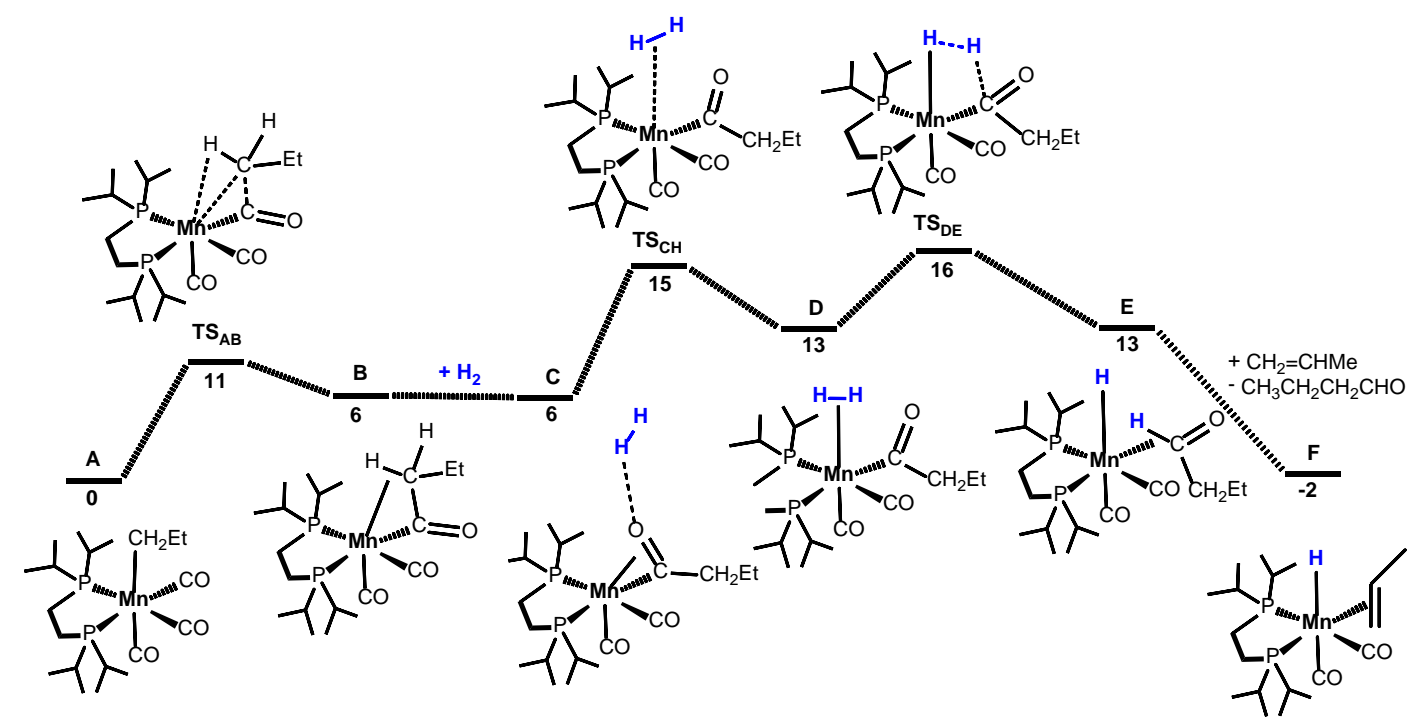

Figure 1. Free Energy Profile Calculated for the Formation and Hydrogenolysis an Acyl Intermediate. Free Energies (kcal/mol) are Referred to $\mathrm{fac}$ - $\left[\mathrm{Mn}\right.$ (dippe) $\left.(\mathrm{CO})_{3}\left(\mathrm{CH}_{2} \mathrm{CH}_{2} \mathrm{CH}_{3}\right)\right](6)$ (A in the calculations).

The free energy profile calculated for the catalytic reaction is depicted in Figure 2. Starting point is the hydride olefin complex F which is the active species of the catalytic reaction. In the first step of the reaction the hydride migrates to the internal olefin C-atom resulting in an alkyl complex stabilized by a C-H agostic interaction in intermediate G. This is a very facile step with a barrier of merely $1 \mathrm{kcal} / \mathrm{mol}$ and a favorable free energy balance of $\Delta G=-5 \mathrm{kcal} / \mathrm{mol}$. The following step corresponds to dihydrogen coordination restoring a saturated coordination environment around the metal in intermediate $\mathrm{I}$. The overall barrier for $\mathrm{H}_{2}$ coordination from intermediate $\mathbf{G}$ to the dihydrogen complex I is $12 \mathrm{kcal} / \mathrm{mol}$ which is the highest one along the path. In the last step of the mechanism $\mathrm{H}$-atom transfer from the dihydrogen ligand to the alkyl C-atom (a formal protonation) regenerates a hydride and forms the final product that remains weakly coordinated as a C-H $\sigma$-ligand in intermediate J. This last step has negligible barrier $(5 \mathrm{kcal} / \mathrm{mol})$ and is strongly exergonic with $\Delta G=$ $25 \mathrm{kcal} / \mathrm{mol}$. Closing of the catalytic cycle brings $\mathrm{J}$ back to $\mathrm{F}$ with liberation of propane and coordination of a new propene molecule in a favorable process with $\Delta G=-13 \mathrm{kcal} / \mathrm{mol}$.

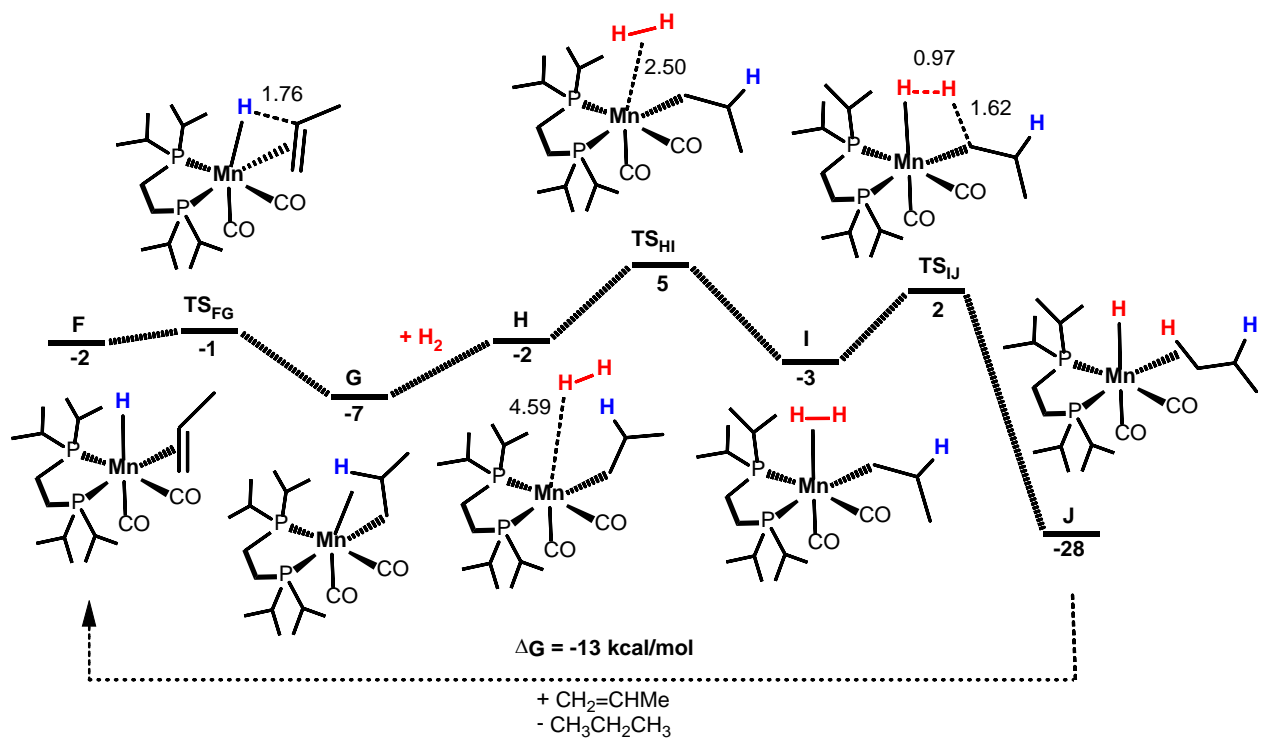

Figure 2. Free Energy Profile Calculated for the Hydrogenation of Propene. Free Energies $(\mathrm{kcal} / \mathrm{mol})$ are Referred to fac$\left[\mathrm{Mn}\right.$ (dippe) $\left.(\mathrm{CO})_{3}\left(\mathrm{CH}_{2} \mathrm{CH}_{2} \mathrm{CH}_{3}\right)\right](6)$ (A in the calculations) 
In sum, an efficient additive-free manganese-catalyzed hydrogenation of alkenes to alkanes with molecular hydrogen is described. To the best of our knowledge, this is the first example of a well-defined $\mathrm{Mn}(\mathrm{I})$-based catalyst for the reduction of unactivated $\mathrm{C}=\mathrm{C}$ bonds with dihydrogen. The most efficient pre-catalyst is the alkyl bisphosphine $\mathrm{Mn}(\mathrm{I})$ complex fac- $\left[\mathrm{Mn}(\operatorname{dippe})(\mathrm{CO})_{3}\left(\mathrm{CH}_{2} \mathrm{CH}_{2} \mathrm{CH}_{3}\right)\right]$ which is air-stable for several weeks. The catalytic process is initiated by migratory insertion of a CO ligand into the Mn-alkyl bond to yield an acyl intermediate which undergoes rapid hydrogenolysis to form the active $16 \mathrm{e}^{-} \mathrm{Mn}(\mathrm{I})$ hydride catalyst $\left[\mathrm{Mn}(\right.$ dippe $\left.)(\mathrm{CO})_{2}(\mathrm{H})\right]-\mathrm{a}$ conceptually new approach in $\mathrm{Mn}(\mathrm{I})$ hydrogenation chemistry. We were able to hydrogenate a range of mono- and disubstituted alkenes to afford alkanes in good to excellent yields with high functional group tolerance. The hydrogenation of monosubstituted alkenes and 1,1-disubstituted alkenes proceeds at $25^{\circ} \mathrm{C}$, while 1,2-disubstituted alkenes require a reaction temperature of $60^{\circ} \mathrm{C}$. In all cases, a catalyst loading of $2 \mathrm{~mol} \%$ and a hydrogen pressure of 50 bar was applied. DFT calculations disclosed a typical inner shell mechanism with all reacting fragments coordinated to the metal. The path involves protonation of the internal $\mathrm{C}=\mathrm{C}$ carbon atom followed by hydride insertion into the $\mathrm{Mn}-\mathrm{C}$ bond of the resulting alkyl.

Table 1 Catalyst Screening for the Synthesis of Dodecane from 1-Dodecene ${ }^{a}$

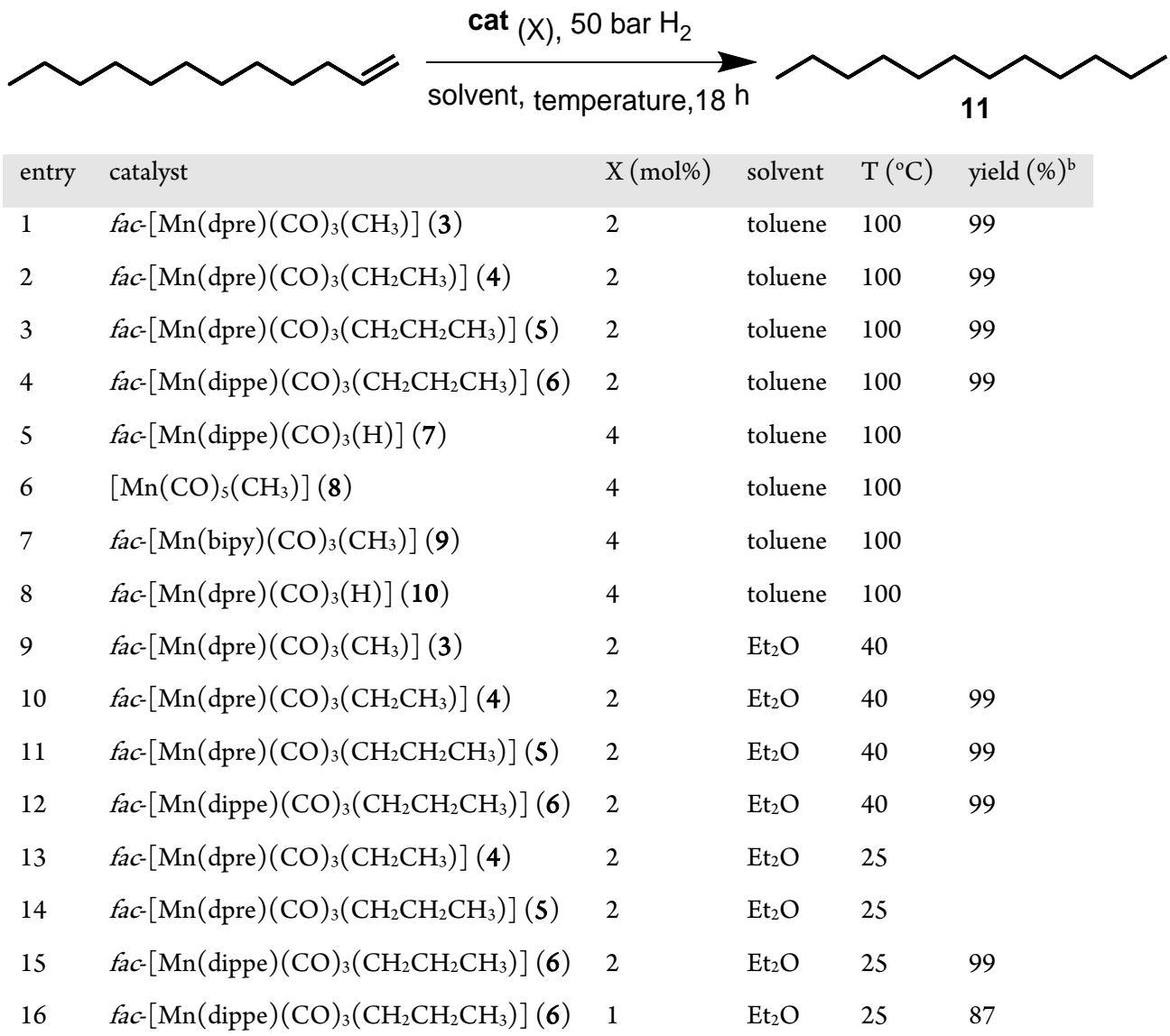

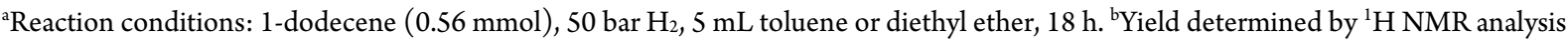
using methyl benzoate as standard. 
Table 2 Hydrogenation of Various Alkenes Catalyzed by fac-[Mn(dippe)(CO) $\left.{ }_{3}\left(\mathrm{CH}_{2} \mathrm{CH}_{2} \mathrm{CH}_{3}\right)\right](6)^{\mathrm{a}}$

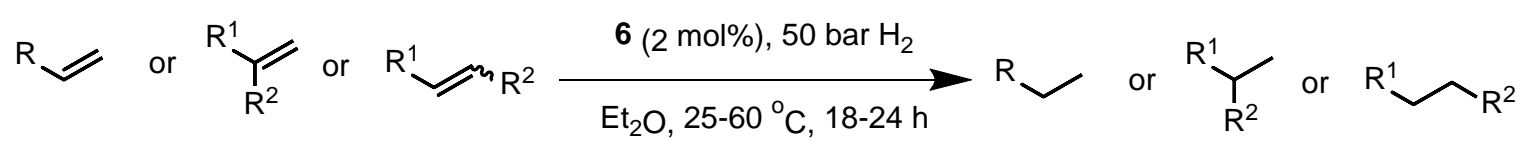

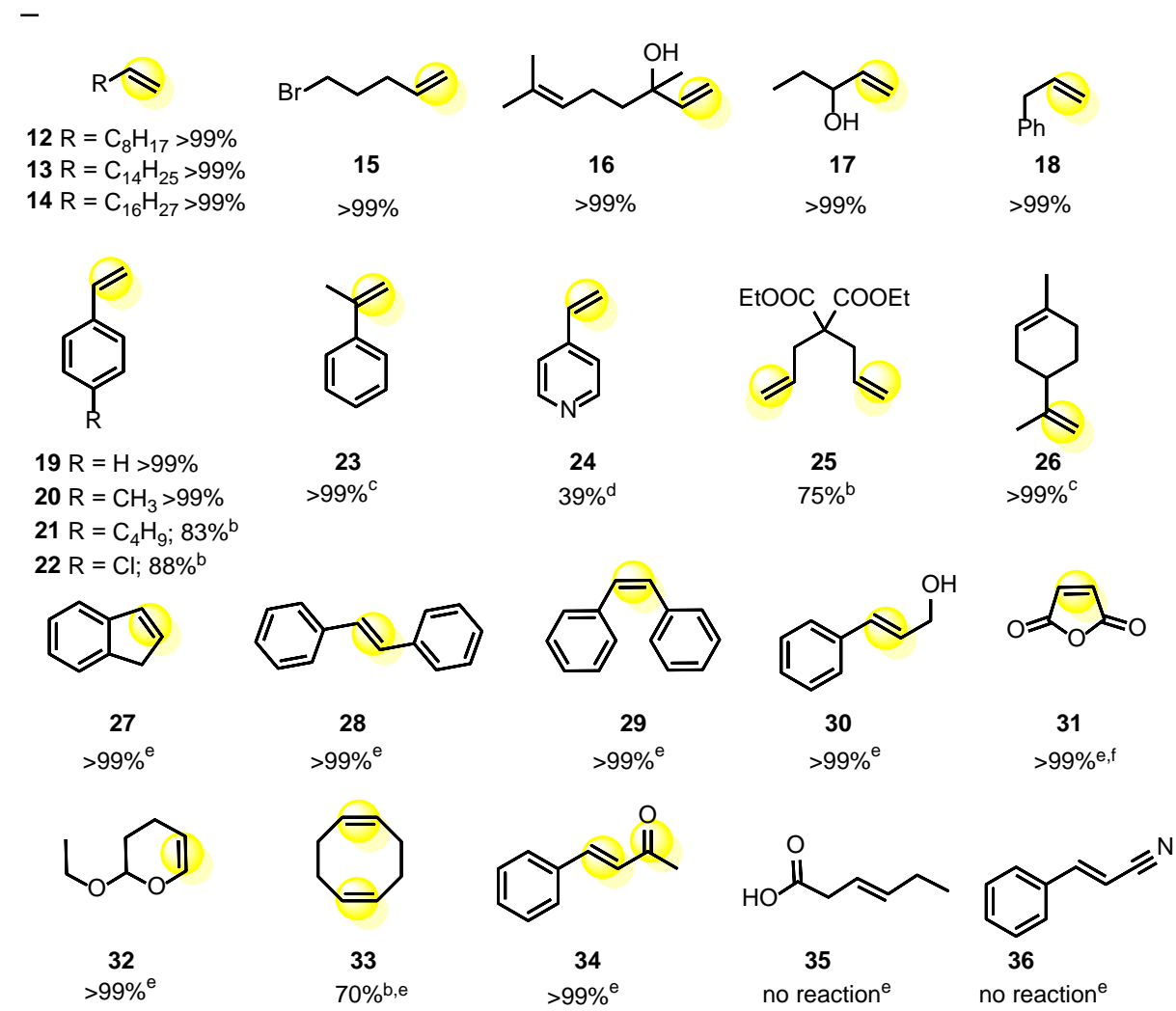

${ }^{a}$ Reaction conditions: substrate $(0.56 \mathrm{mmol})$, fac- $\left[\mathrm{Mn}(\right.$ dippe $\left.)(\mathrm{CO})_{3}\left(\mathrm{CH}_{2} \mathrm{CH}_{2} \mathrm{CH}_{3}\right)\right](6)(2 \mathrm{~mol} \%), 5 \mathrm{~mL}$ of diethyl ether, 50 bar $\mathrm{H}_{2}$, $25{ }^{\circ} \mathrm{C}, 18 \mathrm{~h}$, isolated yields. ${ }^{\mathrm{b}} \mathrm{Conversion}$ determined by GC-MS. $24 \mathrm{~h}$. ${ }^{\mathrm{d} Y i e l d}$ determined by ${ }^{1} \mathrm{H}$ NMR analysis using methyl benzoate as standard. ${ }^{\mathrm{e}} 60^{\circ} \mathrm{C}, 24 \mathrm{~h}$. ${ }^{\mathrm{f}} \mathrm{THF} / \mathrm{CH}_{2} \mathrm{Cl}_{2}(1: 1)$ as solvent.

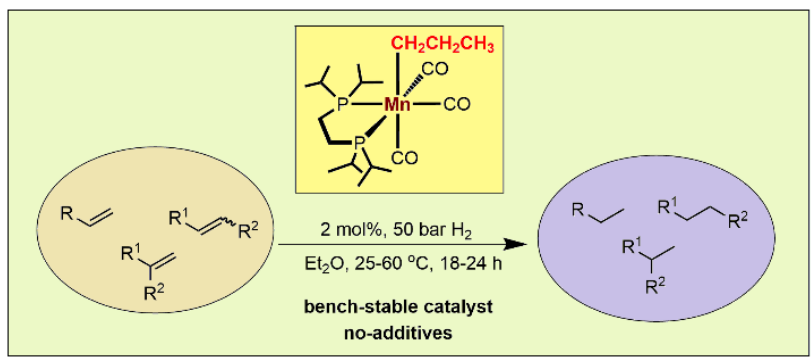




\section{ASSOCIATED CONTENT}

\section{Supporting Information}

The Supporting Information is available free of charge on the ACS Publications website at DOI:

X-ray crystallographic data for 6 (CCDC entry 1920413). (CIF)

Synthetic procedures, ${ }^{1} \mathrm{H},{ }^{13} \mathrm{C}\left\{{ }^{1} \mathrm{H}\right\}$, and ${ }^{31} \mathrm{P}\{\mathrm{H}\}$ NMR spectra of all compounds, crystallographic data and complete computational details (PDF)

Cartesian coordinates for DFT-optimized structures (XYZ)

\section{AUTHOR INFORMATION}

\section{Corresponding Author}

*K.K.: e-mail, karl.kirchner@tuwien.ac.at, tel (+43) 158801 163611; fax (+43) 15880116399.

\section{ORCID}

Karl Kirchner: 0000-0003-0872-6159

Luis Veiros: 0000-0001-5841-3519

\section{Notes}

The authors declare no competing financial interest.

\section{ACKNOWLEDGMENT}

Financial support by the Austrian Science Fund (FWF) is gratefully acknowledged (Project No. P29584-N28). LFV acknowledges Fundação para a Ciência e Tecnologia, UID/QUI/00100/2013.

\section{References}

(1) Bullock, R. M. (Ed.), Catalysis without Precious Metals, Wiley-VCH: Weinheim, 2010. I

(2) Blaser, H.-U.; Spindler, F.; Thommen, M. In The Handbook of Homogeneous Hydrogenation; de Vries, J. G., Elsevier, C. J., Eds.; Wiley-VCH: Weinheim, 2008; Chapter 37, pp 1279-1324.

(3) Gieshoff, T. N.; von Wangelin, A. J. In Non-Noble Metal Catalysis: Molecular Approaches and Reactions Klein Gebbink, R. J. M.; Moret, M.-E., Eds.; Wiley-VCH: Weinheim, 2019; Chapter 5, pp 97-126.

(4) Castro, L. C. M.; Li, H.; Sortais, J.-B.; Darcel, C. When Iron Met Phosphines: A Happy Marriage for Reduction Catalysis Green Chem. 2015, 17, 2283-2303.

(6) Zell, T.; Milstein, D. Hydrogenation and Dehydrogenation Iron Pincer Catalysts Capable of Metal-Ligand Cooperation by Aromatization/Dearomatization Acc. Chem. Res. 2015, 48, 1979-1994.

(7) Chakraborty, S.; Bhattacharya, P.; Dai, H.; Guan, H. Nickel and Iron Pincer Complexes as Catalysts for the Reduction of Carbonyl Compounds. Acc. Chem. Res. 2015, 48, 1995-2003.

(8) Mukherjee, A.; Milstein, D. Homogeneous Catalysis by Cobalt and Manganese Pincer Complexes ACS Catal. 2018, 8, $11435-11469$

(9) Kallmeier, F.; Kempe, R. Manganese Complexes for (De)Hydrogenation Catalysis: A Comparison to Cobalt and Iron Catalysts. Angew. Chem., Int. Ed. 2018, 57, 46-60.

(10) Filonenko, G. A.; van Putten, R.; Hensen, E. J. M.; Pidko, E. A. Catalytic (De)hydrogenation Promoted by Non-Precious Metals - Co, Fe and Mn: Recent Advances in an Emerging Field. Chem. Soc. Rev. 2018. 47, 1484-1515.

(11) Gorgas, N.; Kirchner, K. Isoelectronic Manganese and Iron Hydrogenation/Dehydrogenation Catalysts - Similarities and Divergences Acc. Chem. Res. 2018, 51, 1558-1569. 
(12) (a) Chirik, P. J. Iron- and Cobalt-Catalyzed Alkene Hydrogenation: Catalysis with Both Redox-Active and Strong Field Ligands Acc. Chem. Res. 2015, 48, 1687-1695. (b) Arevalo, R.; Chirik, P. J. Enabling Two-Electron Pathways with Iron and Cobalt: From Ligand Design to Catalytic Applications J. Am. Chem. Soc. 2019, 141, 9106-9123.

(13) For recent examples of iron, cobalt, and nickel catalyzed olefin hydrogenations, see: (a) Murphy, L.J.; Ferguson, M.J.; McDonald, R.; Lumsden, M. D.; Turculet, L. Synthesis of Bis(phosphino)silyl Pincer-Supported Iron Hydrides for the Catalytic Hydrogenation of Alkenes Organometallics 2018, 37, 4814-4826. (b) Sunada, Y.; Ogushi, H.; Yamamoto, T.; Uto, S. Sawano, M.; Tahara, A.; Tanaka, H.; Yoshihito Shiota, Y.; Yoshizawa, K.; Nagashima, H. Disilaruthena- and Ferracyclic Complexes Containing Isocyanide Ligands as Effective Catalysts for Hydrogenation of Unfunctionalized Sterically Hindered Alkenes J. Am. Chem. Soc. 2018, 140, 4119-4134. (c) Xu, R.; Chakraborty, S.; Bellows, S. M.; H.; Cundari, T. R.; Jones, W. D. Iron-Catalyzed Homogeneous Hydrogenation of Alkenes under Mild Conditions by a Stepwise, Bifunctional Mechanism ACS Catal. 2016, 6, 2127-2135. (d) Friedfeld, M. R.; Shevlin, M.; Margulieux, G. W.; Campeau, L.-C.; Chirik, P. J. Cobalt-Catalyzed Enantioselective Hydrogenation of Minimally Functionalized Alkenes: Isotopic Labeling Provides Insight into the Origin of Stereoselectivity and Alkene Insertion Preferences J. Am. Chem. Soc. 2016, 138, 3314-3324. (e) Tokmic, K.; Markus, C. R.; Zhu, L.; Fout, A. R. Well-Defined Cobalt(I) Dihydrogen Catalyst: Experimental Evidence for a Co(I)/Co(III) Redox Process in Olefin Hydrogenation J. Am. Chem. Soc. 2016, 138, 11907-11913. (f) Sandl, S.; Maier, T. M.; van Leest, N. P.; Kröncke, S.; Chakraborty, U.; Demeshko, S.; Koszinowski, K.; de Bruin, B.; Meyer, F.; Bodensteiner, M.; Herrmann, C.; Wolf, R.; Jacobi von Wangelin, Cobalt-Catalyzed Hydrogenations via Olefin Cobaltate and Hydride Intermediates A. ACS Catal. 2019, in press (DOI: 10.1021/acscatal.9b01584). (g) Wang, Y.; Kostenko, A.; Sheglai Yao, S.; Driess, M. Divalent Silicon-Assisted Activation of Dihydrogen in a Bis(N-heterocyclic silylene)xanthene Nickel(0) Complex for EfficientCatalytic Hydrogenation of Olefins J. Am. Chem. Soc. 2017, 139, 13499-13506. (h) Léonard, N. G.; Chirik, P. J. Air-Stable $\alpha$-Diimine Nickel Precatalysts for the Hydrogenation of Hindered, Unactivated Alkenes ACS Catal. 2018, 8, 342-348.

(14) Garbe, M.; Junge, K.; Beller, M. Homogeneous Catalysis by Manganese-Based Pincer Complexes. Eur.J. Org. Chem. 2017, 43444362.

(15) Maji, B.; Barman, M. Recent Developments of Manganese Complexes for Catalytic Hydrogenation and Dehydrogenation Reactions. Synthesis 2017, 49, 3377-3393.

(16) (a) Chakraborty, U.; Reyes-Rodriguez, E.; Demeshko, S.; Meyer, F.; Jacobi von Wangelin, A. A Manganese Nanosheet: New Cluster Topology and Catalysis Angew. Chem. Int. Ed. 2018, 57, 4970-4975. (b) Chakraborty, U.; Demeshko, S.; Meyer, F.; Jacobi von Wangelin, A. Synthesis and Reactivity of an Early-Transition-Metal Alkynyl Cubane $\mathrm{Mn}_{4} \mathrm{C}_{4}$ Cluster Angew. Chem. Int. Ed. 2019, 58, $3466-3470$.

(17) Calderazzo, F. Synthetic and Mechanistic Aspects of Inorganic Insertion Reactions. Insertion of Carbon Monoxide Angew. Chem. Int. Ed. 1977, 16, 299-311.

(18) Ojima, I.; Tsai, C.-Y.; Tzamarioudaki, M.; Bonafoux, D. The Hydroformylation Reaction; Wiley: New York, 2004.

(19) Garduño, J. A.; Garcia, J. J. Non-Pincer Mn(I) Organometallics for the Selective Catalytic Hydrogenation of Nitriles to Primary Amines ACS Catal. 2018 9, 392-401.

(20) Coffield, T. H.;.Closson, R. D; Kozikowski, J. Acyl Manganese Pentacarbonyl Compounds J. Org. Chem. 1957, $22,598$.

(21) Garete Alonso, F. J; Llamazares, A.; Riera, V.; Vivanco, M. Effect of a nitrogen-nitrogen chelate ligand on the insertion reactions of carbon monoxide into a manganese-alkyl bond Organometallics 1992 11, 2826-2832.

(22) Weber, S.; Stöger, B.; Kirchner, K. Hydrogenation of Nitriles and Ketones Catalyzed by an Air-Stable Bisphosphine Mn(I) Complex Org. Lett. 2018 20, 7212-7215.

(23) Andersen, J.-A. M.; Moss, J. R. Synthesis of an Extensive Series of Manganese Pentacarbonyl Alkyl and Acyl Compounds: Carbonylation and Decarbonylation Studies on $\left[\mathrm{Mn}(\mathrm{R})(\mathrm{CO})_{5}\right]$ and $\left[\mathrm{Mn}(\mathrm{COR})(\mathrm{CO})_{5}\right]$ Organometallics 1994, 13, 5103-5020.

(24) (a) Parr, R. G.; Yang, W. Density Functional Theory of Atoms and Molecules; Oxford University Press: New York, 1989. (b) Calculations performed at the PBE0/(SDD, 6-31G**) level using the GAUSSIAN 09 package. All calculations included solvent effects 
(diethyl ether) using the PCM/SMD model. A full account of the computational details and a complete list of references are provided as SI. 